Bài báo khoa học

\title{
Nghiên cứu cảnh báo sét bằng nguồn số liệu tổng hợp, thử nghiệm cho khu vực Gia Lâm, Thành phố Hà Nội
}

\author{
Hoàng Hải Sơn ${ }^{1,2 *}$, Nguyễn Xuân Anh ${ }^{1,2}$, Phạm Xuân Thành ${ }^{1,2}$, Nguyễn Văn Hiệp ${ }^{1,3}$ \\ ${ }^{1}$ Viện Vật lý Địa cầu, hhson@igp-vast.vn; anhnx@igp-vast.vn; pxthanh@igp-vast.vn \\ ${ }^{2}$ Học viện Khoa học và Công nghệ, hhson@igp-vast.vn; anhnx@igp-vast.vn; pxthanh@ \\ igp-vast.vn \\ ${ }^{3}$ Đài KTTV khu vực Đồng bằng Bắc Bộ; hiepwork@gmail.com \\ * Tác giả liên hệ: hhson@igp-vast.vn; Tel.: +84-984863042
}

Ban Biên tập nhận bài: 20/10/2020; Ngày phản biện xong: 28/11/2020; Ngày đăng bài: $25 / 12 / 2020$

Tóm tắt: Bài báo này nghiên cứu, đánh giá, xây dựng quy trình cảnh báo sét cho khu vực Gia Lâm-Hà Nội. Sử dụng các nguồn số liệu gồm: 139 ngày có nhiễu loạn cường độ điện trường trên tổng số 521 ngày đo đạc của thiết bị đo cường độ điện trường $(\mathrm{EFM}-100)$ đặt tại trạm Phú Thụy thuộc Gia Lâm-Hà Nội, trong khoảng thời gian từ 2017 đến 2019; số liệu định vị sét; số liệu radar thời tiết; số liệu vệ tinh Himawari. Phương pháp cảnh báo được áp dụng là phương pháp "hai vùng", vùng cần cảnh báo $\mathrm{AOC}$ với bán kính $10 \mathrm{~km}$ từ vị trí trạm đo điện trường và vùng cảnh báo WA (mở rộng thêm $20 \mathrm{~km}$ từ vùng $\mathrm{AOC}$ ). Các chỉ số thống kê được dùng để đánh giá chất lượng cảnh báo, theo thời gian cả ngày và buổi chiều, kết quả cho thấy tỷ lệ cảnh báo đúng $\mathrm{POD}$ cho vùng $\mathrm{AOC}$ tương ứng là $86,99 \%$ và $88,0 \%$. Tỷ lệ cảnh báo không thành công FTW cho vùng $\mathrm{AOC}$ tương ứng là $13,01 \%$ và $12,0 \%$. Tỷ lệ cảnh báo khống $\mathrm{FAR}$ tương ứng là $24,14 \%$ và $18,52 \%$. Thời gian cảnh báo sét trung bình là trước 31,6 phút, đây là thời gian khá hữu ích cho công tác chuẩn bị phòng tránh sét cho nhiều lĩnh vực trong đời sống xã hội.

Từ khóa: Điện trường khí quyển; Định vị sét; Radar thời tiết; Ảnh mây vệ tinh.

\section{Mở đầu}

Việt Nam nằm ở tâm dông Châu Á, một trong ba tâm dông trên thế giới, có dông sét mạnh. Hoạt động sét ảnh hưởng trực tiếp đến kinh tế xã hội, đến quá trình công nghiệp hóa hiện đại hóa đất nước. Trong gần ba thập kỷ gần đây, rất nhiều công trình, đường dây tải điện, kho tàng, các thiết bị ngành bưu chính viễn thông, sân bay, khu công nghiệp, thiết bị nghiên cứu khoa học, thiết bị nổ mìn,....v.v, đã bị sét đánh hỏng hoặc phá hủy hoàn toàn, gây thiệt hại rất lớn. Ngoài thiệt hại về kinh tế, sét còn gây thiệt hại về người, gây tâm lý hoang mang cho con người [1-6]. Do đó việc cảnh báo và phòng chống sét ngày càng trở nên hữu ích. Trong đó việc cảnh báo sét là một công việc quan trọng, cần được quan tâm, việc này sẽ hỗ trợ tốt cho việc phòng chống sét. Tuy nhiên, việc cảnh báo sét đòi hỏi nhiều vấn đề liên quan, cụ thể là các nguồn số liệu sử dụng, khu vực cảnh báo, phương pháp xử lý số liệu, phương pháp cảnh báo và phương pháp đánh giá kết quả cảnh báo.

Vấn đề nghiên cứu cảnh báo sét cho một khu vực cụ thể đã và đang được thực hiện ở nhiều nơi bởi nhiều nhà nghiên cứu sét trong các công trình [7-24]. Tuy vậy các hệ thống định vị sét trong các nghiên cứu nói trên có nhiều dạng khác nhau. Một số hệ thiết bị định vị sét có chi phí khá đắt và vì vậy các nước chưa có tiềm lực kinh tế mạnh khó có khả năng đầu tư. Cũng có một số hệ thiết bị thiết có chi phí thấp, tuy nhiên số liệu của nó, có độ chính xác 
chưa cao, hiệu suất phát hiện thấp, sai số lớn và số liệu cần phải xử lý thêm. Các nghiên cứu cho thấy chất lượng cảnh báo sét phụ thuộc chủ yếu vào: nguồn số liệu sử dụng, phương pháp xử lý số liệu, phương pháp cảnh báo sét và tính chất địa phương của hoạt động dông sét. Nhóm tác giả trong công trình [19], thực hiện cảnh báo sét cho khu vực Nanjing-Trung Quốc dựa trên số liệu của 5 trạm đo cường độ điện trường, 2 trạm radar thời tiết và số liệu của hệ thống định vị sét LLS (Lightning Location System). Thời gian trung bình cảnh báo trước phóng điện mây-đất đầu tiên $\mathrm{LT}=20,8$ phút với khả năng cảnh báo sét thành công trên $80 \%$. Nhóm tác giả trong công trình [8], cũng đã thực hiện cảnh báo sét cho khu vực LouisvilleHoa Kỳ, dựa trên số liệu định vị sét quốc gia NLDN (National Lightning Detection Network) của Mỹ và số liệu đo điện trường, cho kết quả cảnh báo sét trước 2 phút với khả năng cảnh báo sét thành công $100 \%$, thời gian trung bình cảnh báo trước (LT: lead time) phóng điện mây-đất đầu tiên là 20 phút. Nhìn chung thời gian cảnh báo sét trước đã được nhiều tác giả kể trên đưa ra, giá trị này thay đổi từ một vài phút đến khoảng hơn 30 phút, giá trị này càng lớn thì càng có ý nghĩa thực tiễn. Độ chính xác của phương pháp cảnh báo sét được đánh giá bằng các chỉ số thống kê như: $\mathrm{POD}$ (xác suất phát hiện hay còn gọi là tỷ lệ cảnh báo đúng), FTW (tỷ lệ cảnh báo không thành công), FAR (tỷ lệ cảnh báo khống), giá trị này phụ thuộc vào nhiều yếu tố, trong đó có thiết bị đo, phương pháp và vị trí nghiên cứu,...v.v.

Tại Việt Nam vấn đề nghiên cứu dông sét nói chung hay điện khí quyển nói riêng đã được một số cơ quan, tổ chức, cũng như một số cá nhân thực hiện. Năm 1957, được sự giúp đỡ của chính phủ Ba Lan, nhân dịp năm Quốc tế Vật lý Địa cầu, bộ môn điện khí quyển, tiền thân của Phòng Vật lý khí quyển thuộc Viện Vật lý Địa cầu ngày nay đã được thành lập. Tiếp sau đó, trong khoảng thời gian gần đây, với sự phát triển của khoa học kỹ thuật và để đáp ứng được nhu cầu phát triển đất nước đã có nhiều công trình nghiên cứu về dồng sét được tiến hành. Một số công trình nghiên cứu sét cũng đã được thực hiện bên Ngành điện lực từ trước năm 2000, đã được tổng quan trong các công trình $[1,4]$, tuy vậy các nghiên cứu này cũng chưa đề cập đến vấn đề cảnh báo sét, mà chỉ tập chung nghiên cứu về vấn đề mật độ sét, độ dốc dòng điện sét, định vị sét và chống sét,...v.v, áp dụng của nó chỉ hạn chế trong Ngành điện lực. Bên Ngành Khí tượng Thủy văn, thời gian gần đây cũng có các nghiên cứu cảnh báo dông hay dự báo dông, là hiện tượng kèm theo sét, theo một số phương pháp khác nhau và nguồn số liệu sử dụng chủ yếu dựa vào số liệu radar thời tiết, ảnh mây vệ tinh hoặc quan trắc synop và vấn đề chính vẫn là cảnh báo dông, dự báo dông hoặc theo dõi dông. Tuy nhiên, bản chất của sét là một hiện tượng điện trong khí quyển và xuất hiện kèm theo các đám mây dông, trong khi đó các nghiên cứu này vẫn chưa gắn với các quan trắc trực tiếp hiện tượng sét hay điện khí quyển. Trong công trình [25], thực hiện năm 2018, nhóm tác giả có sử dụng số liệu định vị sét, tuy nhiên chỉ dừng lại ở sử dụng vị trí sét với số liệu radar để cảnh báo mưa lớn.

Trên cơ sở các nghiên cứu trước đây về dông sét tại Viện Vật lý Địa cầu của nhiều tác giả, đã được tổng quan trong $[1,4]$. Hay các công trình trong thời gian gần đây như các đề tài hay công trình nghiên cứu về dông sét [1-6] thực hiện, đã cho các kết quả đáng kể trong lĩnh vực phòng chống sét, áp dụng hiệu quả cho nhiều đơn vị trong các ngành nghề khác nhau như: sân bay, xăng dầu, điện lực, dầu khí, du lịch,...v.v. Ngoài ra trong khuôn khổ thực hiện trong dự án FIRST tại Viện Vật lý Địa cầu, tại khu vực Hà Nội có thêm 08 thiết bị đo điện trường, 02 radar thời tiết dải $X$-band phân cực kép với độ phân giải tới $200 \mathrm{~m}$, đã đi vào hoạt động từ tháng 10 năm 2019, các kết quả nghiên cứu về dự báo mưa lớn, cảnh báo dông sét,...v.v, cho phép nghiên cứu chi tiết hơn về cảnh báo sét cho khu vực Hà Nội. Trong các đề tài $[1,4]$, nhóm tác giả đã bước đầu thử nghiệm cảnh báo sét tại Quảng Nam và Hà Nội. Từ năm 2017, tại trạm Vật lý khí quyển Phú Thụy thuộc Gia Lâm-Hà Nội, được trang bị thiết bị đo cường độ điện trường, dùng cho mục đích nghiên cứu cơ cấu điện tích mây dông, định vị sét và cảnh báo sét, với dải đo mở rộng hơn trước $( \pm 20 \mathrm{kV} / \mathrm{m})$. Gần đây các nguồn số liệu khác liên quan như định vị sét, số liệu radar, số liệu vệ tinh đã được cập nhật và nâng 
cấp. Vì vậy chúng ta cần tiến hành các nghiên cứu cập nhật bổ sung trong lĩnh vực cảnh báo sét cho khu vực Gia Lâm-Hà Nội.

\section{Số liệu và phương pháp}

\subsection{Số liệu}

Các nguồn số liệu sử dụng trong nghiên cứu này bao gồm: số liệu cường độ điện trường, số liệu vệ tinh, số liệu radar thời tiết và số liệu định vị sét. Số liệu đo cường độ điện trường được quan trắc tại trạm Phú Thụy thuộc Gia Lâm-Hà Nội (EFM-100: Electric Field Mill100 , vị trí trạm: $\left.21,028^{\circ} \mathrm{N} ; 105,958^{\circ} \mathrm{E}\right)$. Số liệu radar cung cấp bởi Đài Khí tượng Cao không (http://www.amo.gov.vn), số liệu ảnh mây vệ tinh Himawari kênh hồng ngoại cung cấp bởi Đại học Chi Ba, Nhật Bản (http://www.cr.chiba-u.jp/databases/GEO/). Số liệu định vị sét được quan trắc tại trạm định vị sét Nghĩa Đô-Viện Vật lý Địa cầu.Và nguồn số liệu định vị sét khác, được thu thập từ trang web: http://promoserv.amo.gov.vn/lightnings/GLDascii/, đây là một trong những sản phẩm của dự án hợp tác giữa Tổng cục Khí tượng Thủy văn và Viện Khí tượng Thủy văn Phần Lan [25].

Sơ đồ hệ thống thiết bị đo điện trường Phú Thụy được mô tả trong hình 1. Hệ thống thiết bị bao gồm bộ cảm biến để ngoài trời, dây cáp nguồn, dây cáp quang truyền số liệu, dây nối đất, mô đun nguồn và mô đun truyền số liệu. Số liệu từ cảm biến có thể truyền qua các mô đun này trực tiếp đến máy tính qua cổng RS232 hoặc cổng USB, được ghi lại bằng phần mềm của nhà sản xuất hoặc chương trình tự viết trên các hệ điều hành khác nhau. Dải đo thiết bị từ $-20 \mathrm{kV} / \mathrm{m}$ đến $+20 \mathrm{kV} / \mathrm{m}$, thời gian đáp ứng 0,1 giây, độ chính xác $0,01 \mathrm{kV} / \mathrm{m}$. Khối lượng hệ thiết bị EFM-100 khoảng $1 \mathrm{~kg}$, phần mềm hiển thị số liệu chạy trên hệ điều hành Windows.

\subsection{Phương pháp}

Để cảnh báo sét cho khu vực Gia Lâm-Hà Nội, chúng tôi sử dụng phương pháp hai vùng (Two area method) (Hình 2). Phương pháp này đã được sử dụng trong nhiều công trình nghiên cứu trên thế giới như trong $[8,13,17,21]$. Các tham số cơ bản của phương pháp gồm: điểm quan tâm (Point of Interest: $P I$ ), tương ứng với vị trí đặt thiết bị đo cường độ điện trường tại trạm Phú Thụy thuộc Gia Lâm-Hà Nội; vùng quan tâm hay vùng cần cảnh báo (Area Of Concern: $A O C$ ) tương ứng diện tích hình tròn bán kính $10 \mathrm{~km}$, với tâm đường tròn là vị trí đặt thiết bị EFM-100 tại trạm Phú Thụy; vùng cảnh báo (Warning Area: WA) tương ứng với hình vành khuyên có bán kính từ $10 \mathrm{~km}$ đến $30 \mathrm{~km}$, bao quanh vùng $\mathrm{AOC}$; $\mathrm{CG}$ (Cloud-Ground) là phóng điện mây-đất của mây dông (có thế là phóng điện dương hoặc phóng điện âm), IC (Intra Cloud) là phóng điện trong mây của mây dông. Phương pháp hai vùng là phương pháp sử dụng thông tin vùng cảnh báo WA để cảnh báo cho vùng quan tâm $\mathrm{AOC}$, trong nghiên cứu này chúng tôi chỉ quan tâm đến phóng điện mây đất $\mathrm{CG}$ cho bài toán cảnh báo sét. Để kiểm tra sự tồn tại của các vùng mây đối lưu (giới hạn xung quanh trạm EFM-100 Phú Thụy khoảng $50 \mathrm{~km}$ ) có thể phát triển hoặc di chuyển đến khu vực nghiên cứu. Chúng tôi sử dụng số liệu radar là các vùng mây có độ phản hồi lớn hơn $35 \mathrm{dBz}$ hoặc số liệu vệ tinh, sử dụng kết hợp số liệu các kênh hồng ngoại TIR6 $(6,2 \mu \mathrm{m})$, TIR2 $(11,2 \mu \mathrm{m})$, kênh TIR2 biểu thị mức độ đóng băng ở đỉnh mây và tốc độ phát triển của mây, chênh lệch TIR6-TIR2 biểu thị độ dày của mây $[22,27,28]$. Số liệu định vị sét sử dụng trong nghiên cứu này để nghiên cứu, đánh giá khả năng cảnh báo sét cho khu vực nghiên cứu. 

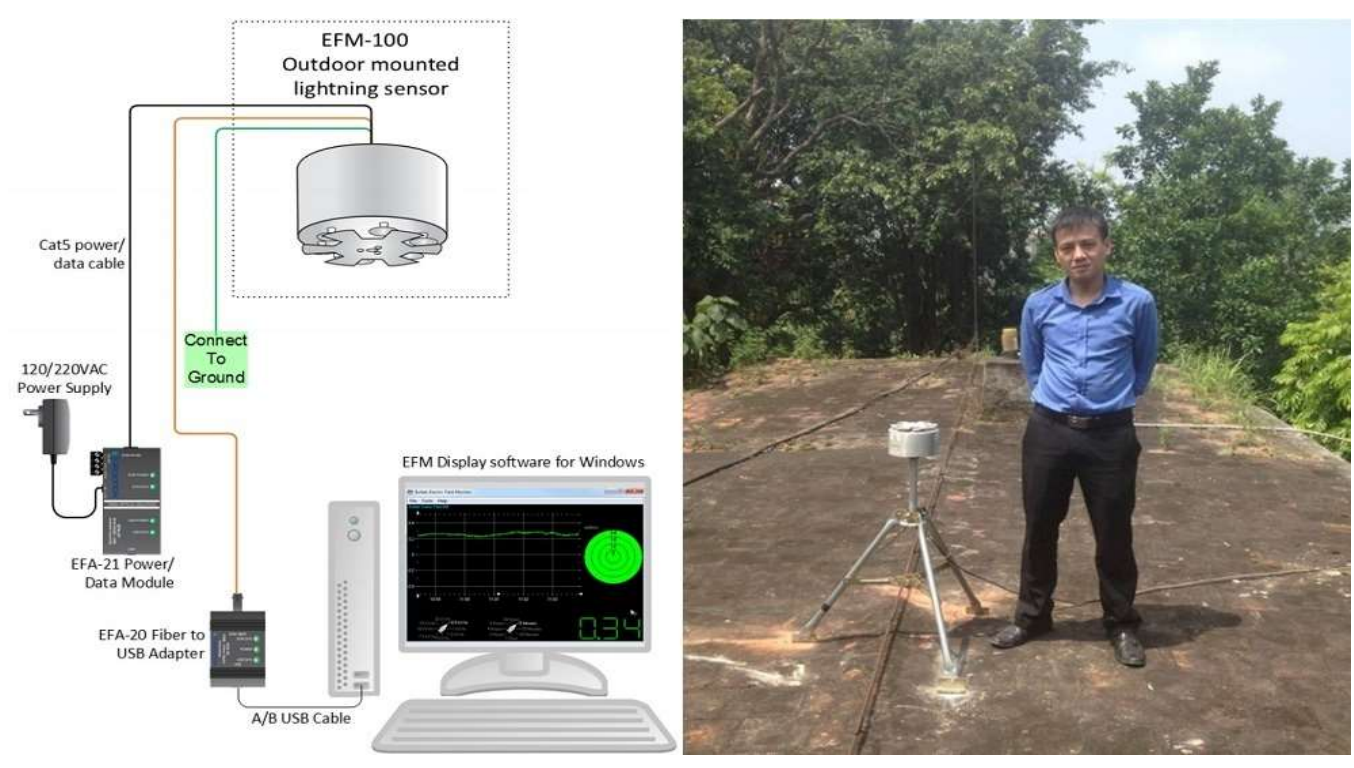

Hình 1. Sơ đồ hệ thống thiết bị đo cường độ điện trường EFM-100 [26] và bộ cảm biến ngoài trời tại trạm Phú Thụy, Gia Lâm-Hà Nội.

Các chỉ số thống kê được sử dụng để đánh giá khả năng cảnh báo sét gồm: Tỷ lệ cảnh báo đúng (POD: Probability Of Detection, có sét có cảnh báo); Tỷ lệ cảnh báo không thành công (FTW: Failure to Warn, có sét không cảnh báo); Tỷ lệ cảnh báo khống (FAR: False Alarm Ratio, không có sét nhưng cảnh báo):

$$
\begin{aligned}
& \text { POD }=\frac{\text { SUC }}{\text { CGAOC }} \\
& \text { FTW }=1-\text { POD } \\
& \text { FAR }=\frac{\text { FA }}{\text { FA+SUC }}
\end{aligned}
$$

Trong đó SUC (SUCcessfull) là số cảnh báo thành công; CGAOC (Cloud-Ground in $A O C$ ) số cảnh báo có tối thiểu một phóng điện mây-đất trong vùng AOC. FA (False Alarm) là cảnh báo sai, tức là cảnh báo sét được kích hoạt, trong khi đó không xẩy ra phóng điện mây-đất nào trong vùng AOC. Ngoài ra còn tham số LT (Lead Time) là thời gian cảnh báo, tức là khoảng thời gian từ khi bắt đầu cảnh báo đến khi xẩy ra phóng điện mây-đất đầu tiên trong vùng $\mathrm{AOC}$.

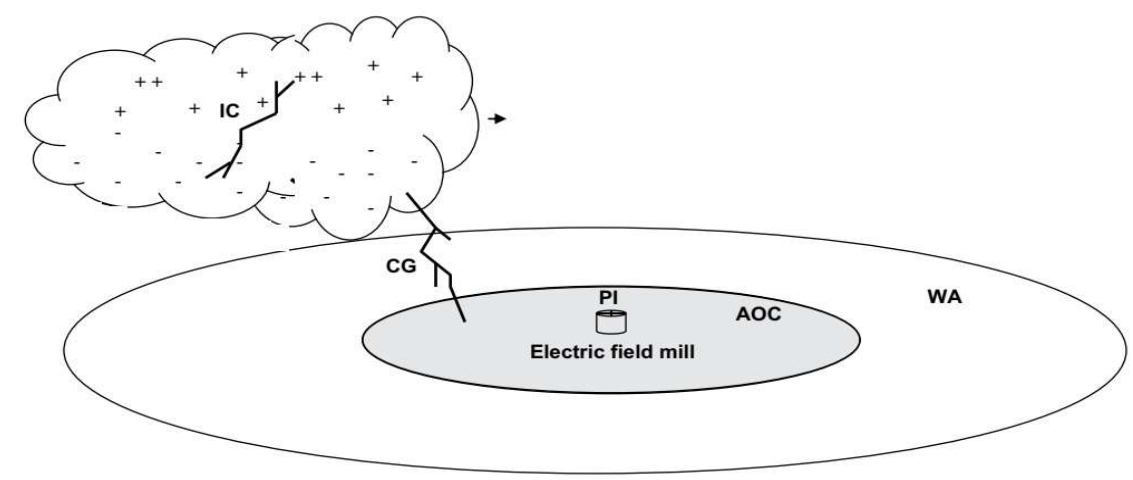

Hình 2. Phương pháp cảnh báo sét dựa trên dựa trên thiết bị đo cường độ điện trường tại một điểm ở bề mặt [13]. 
Để thấy được một cách tổng quát ảnh hưởng của điều kiện thời tiết đến biến đổi điện trường ở bề mặt đo tại trạm Phú Thụy thuộc Gia Lâm-Hà Nội, chúng ta xem hình 3 và hình 4. Hình 3 mô tả biến đồi cường độ điện trường trung bình theo thời gian trong ngày trong điều kiện thời tiết đẹp (không xẩy ra mưa hoặc dông sét tại trạm). Giá trị biến đổi này là trung bình của 382 ngày đo, trong khoảng thời gian có đo đạc số liệu từ năm 2017 đến 2019. Biến đổi điện trường trong ngày có thời tiết đẹp tại khu vực trạm Phú Thụy có giá trị dương, nằm trong khoảng từ trên $40 \mathrm{~V} / \mathrm{m}$ đến nhỏ hơn $160 \mathrm{~V} / \mathrm{m}$, giá trị cực đại nằm trong khoảng thời gian từ 8 giờ đến 16 giờ, cực tiểu trong khoảng thời gian 0 giờ đến 6 giờ, giá trị trung bình cả ngày $78,1 \mathrm{~V} / \mathrm{m}$, biến đổi này phù hợp với quy luật chung, biên độ dao động không lớn do môi trường xung quanh tương đối sạch, ít bụi. Hình 4 mô tả biến đổi cường độ điện trường từ 10 giờ đến 20 giờ, ngày 25/07/2019, trong điều kiện xẩy hoạt động sét ở gần trạm Phú Thụy. Từ hình vẽ ta thấy, khoảng từ 10 giờ đến 12 giờ hoạt động sét xẩy ra ở xa trạm và xẩy ra ít, nên biến đổi điện trường ít dao động và có giá trị không quá $1,0 \mathrm{kV} / \mathrm{m}$. Tuy nhiên sau thời điểm 12 giờ đến hơn 18 giờ, mây dông tiến lại gần khu vực trạm, biểu hiện qua số cú sét xẩy ra nhiều và ở gần khu vực trạm hơn, đi kèm đó là dao động điện trường cũng gia tăng, giá trị tuyệt đối cũng lớn hơn $1,0 \mathrm{kV} / \mathrm{m}$, trước thời điểm đó điện trường trở nên âm hơn (nhỏ hơn âm $1 \mathrm{kV} / \mathrm{m}$ ), đây là một dấu hiệu để chúng ta có thể cảnh báo sét cho khu vực. Khoảng từ 17 giờ đến 18 giờ, hoạt động sét xẩy ra gần nhất khu vực trạm Phú Thụy, kiểm tra số liệu radar Phù Liễn và số liệu vệ tinh Himawari vào thời điểm này của ngày 25/07/2019, chúng ta cũng thấy vùng phản hồi có khả năng có dông sét trùng với khu vực theo dõi, đo đạc. Như vậy trong trường hợp này, khi chúng ta sử dụng số liệu điện trường kết hợp với các nguồn số liệu khác, chúng ta có thể cảnh báo chính xác hiện tượng sét đánh. Tuy vậy để khẳng định điều này chúng ta cần sử dụng bộ số liệu dài hơn nữa, sẽ được trình bày trong phần tiếp theo.

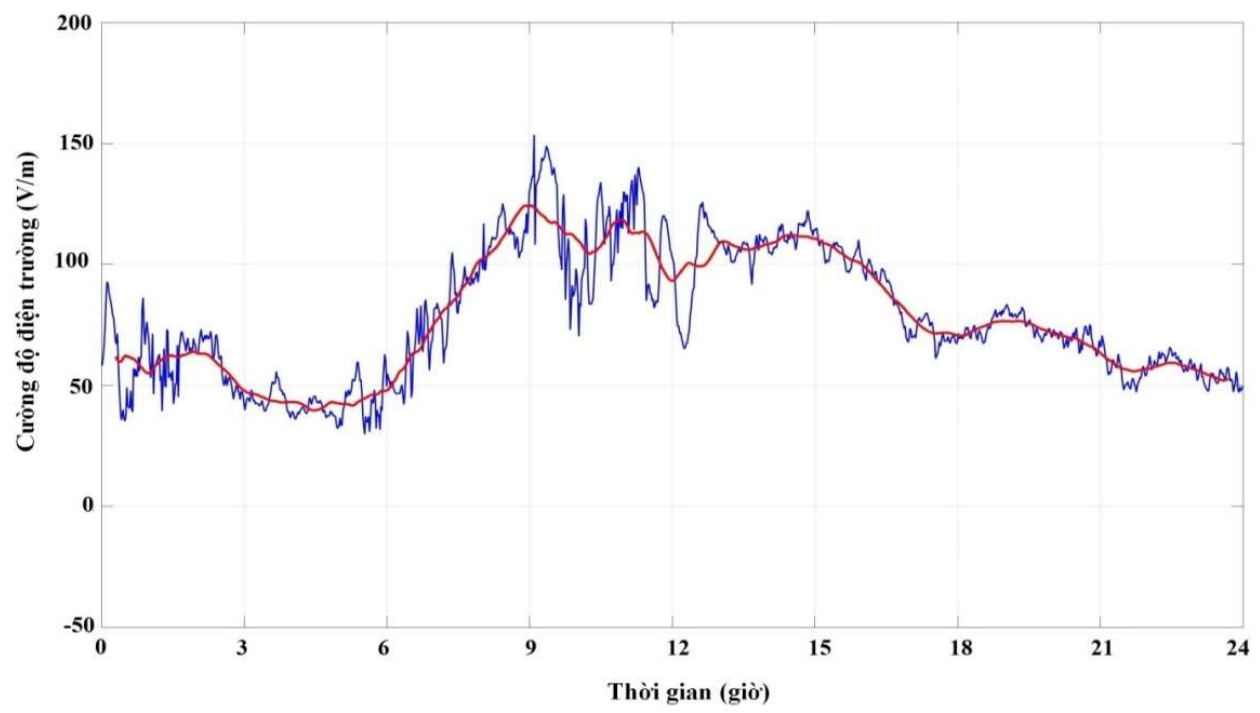

Hình 3. Biến đổi cường độ điện trường trung bình ngày trạm Phú Thụy, giá trị trung bình 382 ngày đo, có điều kiện thời tiết đẹp, trong khoảng thời gian từ 2017 đến 2019.

Công trình [9], Trái đất mang một lượng điện tích âm khoảng $5 \times 10^{5} \mathrm{C}$, trong các điều kiện thời tiết đẹp điện trường ở bề mặt khoảng $130 \mathrm{~V} / \mathrm{m}$. Tuy nhiên, khi mây dông phát triển hoặc dịch chuyển đến một điểm, làm cho điện trường tại điểm dưới mây dông sẽ bị nhiễu loạn và đạt giá trị cao hơn giá trị tuyệt đối $1 \mathrm{kV} / \mathrm{m}$. Do vậy để cảnh báo sét chúng tôi sẽ sử dụng sơ đồ cảnh báo như Hình 5 , với giá trị ngưỡng điện trường tương tự như nghiên cứu [9], nhận dạng mây đối lưu qua số liệu radar hoặc số liệu vệ tinh qua một số tiêu chuẩn trình bày ở trên, đánh giá các kết quả cảnh báo sét như các công thức (1), (2), (3). 


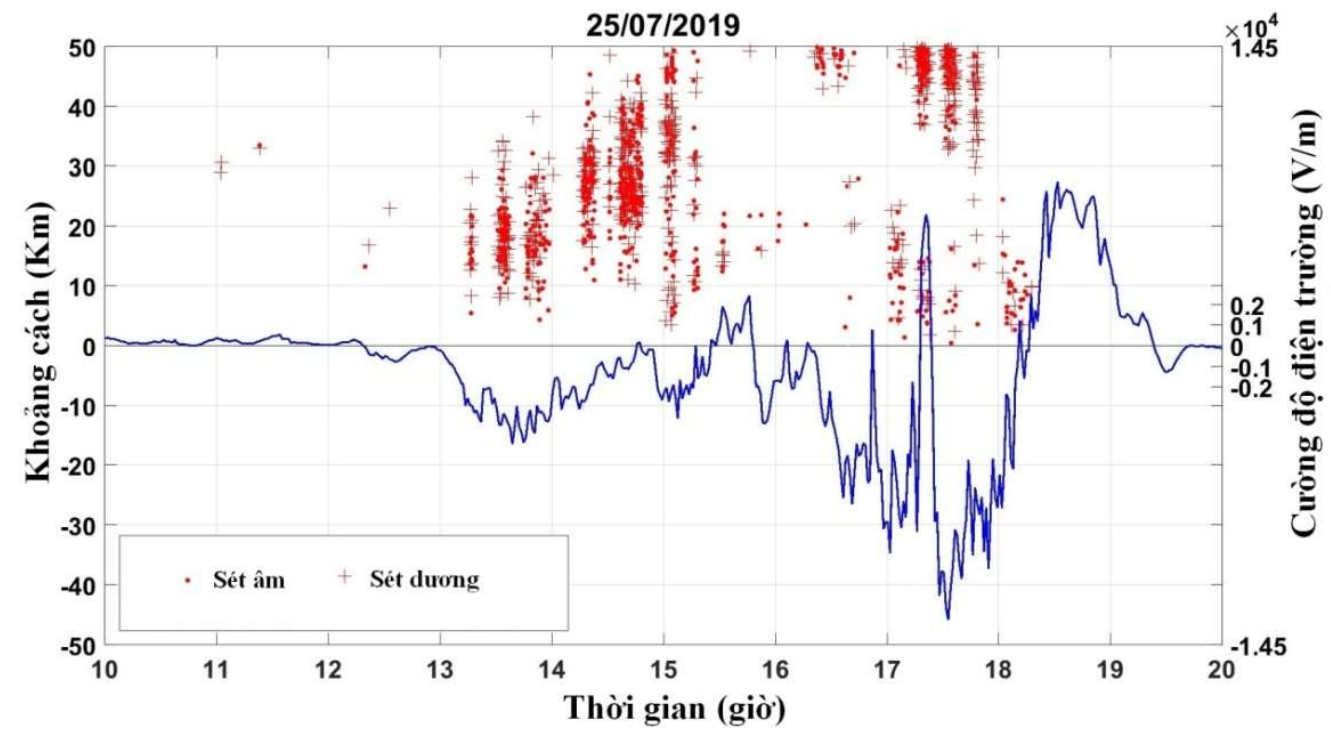

Hình 4. Biến đổi cường độ điện trường trong ngày 25/07/2019 có hoạt động của sét ở gần trạm Phú Thụy.

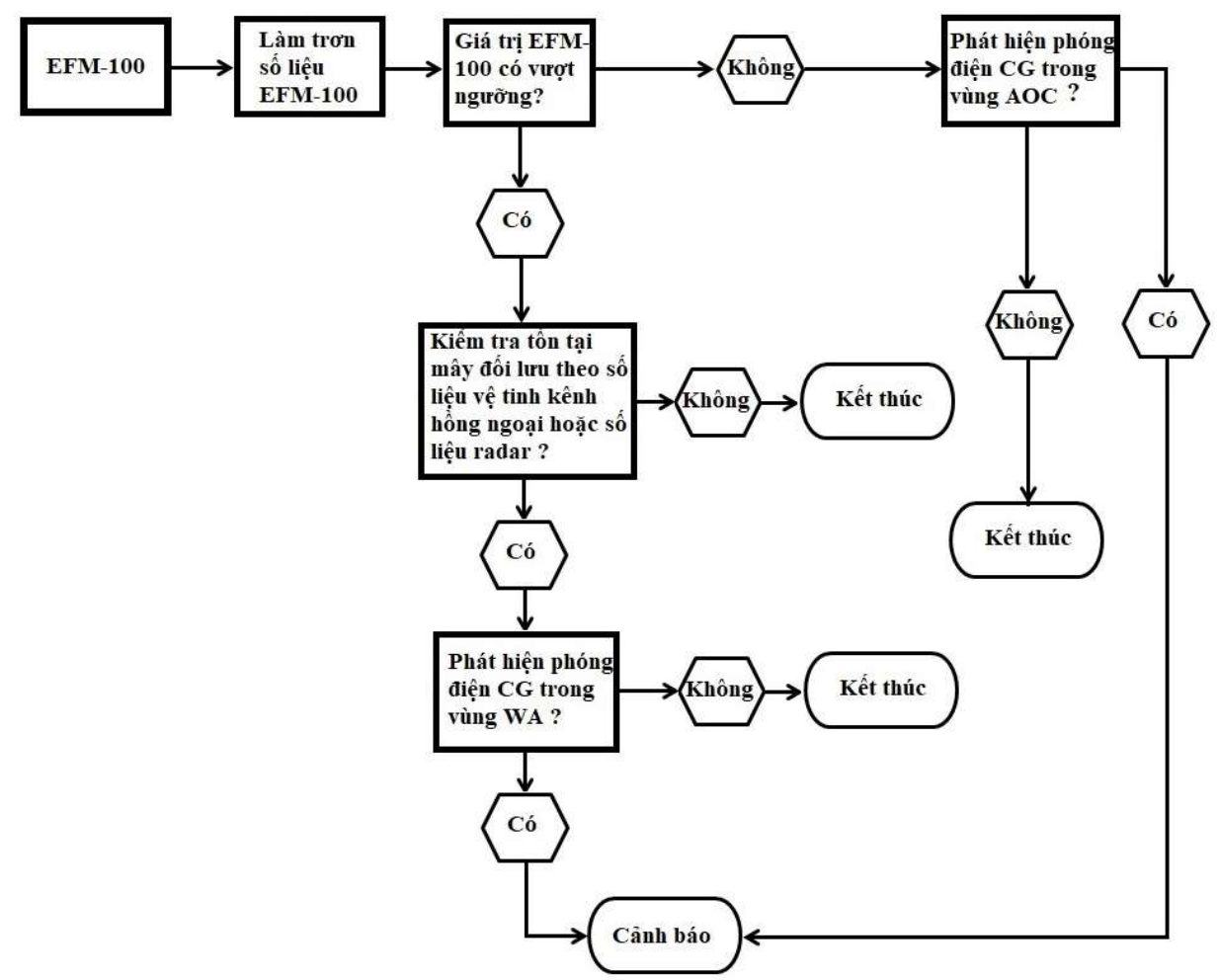

Hình 5. Sơ đồ thuật toán cảnh báo sét [21].

\section{Kết quả nghiên cứu}

Bảng 1 tóm tắt các ngày đo trong giai đoạn từ 2017 đến 2019, tỷ số trong bảng mô tả số ngày từng tháng đo có cường độ điện trường vượt ngưỡng $( \pm 1,0 \mathrm{kV} / \mathrm{m})$ trên tổng số ngày đo của tháng đó. Từ 139 ngày đo có cường độ điện trường vượt ngưỡng, chúng tôi xác định được 97 ngày đo thỏa mãn được các yêu cầu như trong sơ đồ thuật toán đề ra, để nghiên cứu, đánh giá khả năng cảnh báo sét. Các tệp số liệu bị loại do các lý do sau: Không xuất hiện sét 
trong thời gian ở gần thời điểm vượt ngưỡng trong vùng nghiên cứu. Số liệu định vị sét không đảm bảo tính tương quan không gian-thời gian [5]. Sét chỉ xuất hiện ở khoảng cách ngoài 30 $\mathrm{km}$ (mức độ ảnh hưởng đến trạm đo điện trường ít), hoặc không có mây đối lưu trong vùng nghiên cứu. Ngoài ra, trong 97 ngày đo nói trên, chúng tôi xác định được 107 trường hợp thỏa mãn yêu cầu nêu trên, trong đó có những ngày có hoạt động sét xẩy ra tại gần trạm Phú Thụy từ 2 đến 3 lần. Và để thấy được khả năng cảnh báo sét cho khu vực Gia Lâm-Hà Nội theo nguồn số liệu tổng hợp, chúng tôi đã tiến hành nghiên cứu trên một số trường hợp cụ thể, cũng như trên toàn bộ tập số liệu thu thập được.

Hình 6 mô tả biến đổi cường độ điện trường và hoạt động sét trong giới hạn $50 \mathrm{~km}$ xung quanh trạm Phú Thụy, trong khoảng thời gian từ 8 giờ đến 16 giờ, ngày 22/08/2019. Bắt đầu từ khoảng gần 9 giờ đến 11 giờ, hoạt động sét xẩy ra ở khu vực khoảng từ $15 \mathrm{~km}$ đến $50 \mathrm{~km}$ (ở ngoài vùng $\mathrm{AOC}$ ). Cường độ điện trường đo tại trạm Phú Thụy có giá trị dương, không biến đổi nhiều, chưa vượt ngưỡng $\pm 1 \mathrm{kV} / \mathrm{m}$, đến sau thời điểm 11 giờ 24 phút, cường độ điện trường chuyển sang giá trị âm, đạt giá trị vượt ngưỡng (nhỏ hơn $-1 \mathrm{kV} / \mathrm{m}$ ) ở thời điểm 11 giờ 26 phút (thời gian bắt đầu cảnh báo sét: $T_{\mathrm{LW}}$ ), hoạt động sét vẫn xẩy ra ở khu vực cách trạm Phú Thụy từ $15 \mathrm{~km}$ đến $50 \mathrm{~km}$. Kiểm tra số liệu vệ tinh Himawari, kênh TIR2 và chênh lệch nhiệt độ giữa kênh TIR6 và kênh TIR2 (Hình 7). Tại khu vực giới hạn 50 km xung quanh trạm Phú Thụy (dấu sao), có xuất hiện nhiều vùng chênh lệch nhiệt độ ít (gần về giá trị 0 ) biểu thị vùng mây dày hơn các vùng có chênh lệch nhiệt độ lớn. Hơn nữa tại khu vực này, nhiều vùng có nhiệt độ kênh TIR2 nhỏ hơn $220 \mathrm{~K}$, xu thế mây đối lưu đang phát triển. Qua đó, chúng tôi xác định được có tồn tại mây đối lưu tại khu vực nghiên cứu. Thông tin cảnh báo sét khu vực Gia Lâm-Hà Nội, tương ứng với vùng $\mathrm{AOC}$ được được xác định. Đến thời điểm 11 giờ 34 phút (thời gian xác định được sét đầu tiên trong vùng cần cảnh báo: $\mathrm{T}_{\mathrm{LAOC}}$ ), xuất hiện cú sét đầu tiên trong vùng cần cảnh báo, như vậy thông tin cảnh báo đưa ra là chính xác, thời gian cảnh báo sét trước $\mathrm{LT}=8$ phút. Sau thời gian cú sét đầu tiên xẩy ra, hoạt động sét xẩy ra nhiều, trên diện rộng ở khu vực Gia Lâm-Hà Nội và càng tiến gần về phía trạm Phú Thụy gần nhất ở thời điểm gần 13 giờ, vùng mây đối lưu có nhiệt độ đỉnh mây thấp, mây dày (qua kênh TIR2 và TIR6) ở gần trạm Phú Thụy nhất, kể từ thời điểm mây chưa phát triển đến gần trạm. Sau 14 giờ, hoạt động sét giảm dần ở khu vực nghiên cứu, hoạt động sét không xẩy ra ở khu vực cần cảnh báo, đến 15 giờ 30 phút, cường độ điện trường trở lại trạng thái bình thường.

Trong trường hợp tiếp theo, chúng tôi sẽ đưa ra một trường hợp có thời gian cảnh báo sét cho khu vực nghiên cứu có thời gian cảnh báo lớn hơn. Hình 8 mô tả biến đổi cường độ điện trường và hoạt động sét trong giới hạn $50 \mathrm{~km}$ xung quanh trạm Phú Thụy, trong khoảng thời gian từ 11 giờ đến 20 giờ 30 phút, ngày $09 / 09 / 2019$. Trước thời điểm gần 12 giờ 30 phút, hoạt động dông sét không xẩy ra ở khu vực giới hạn $50 \mathrm{~km}$ xung quanh trạm Phú Thụy. Sau thời điểm 12 giờ 30 phút, đến khoảng 14 giờ hoạt động dông sét bắt đầu xẩy ra trong khoảng từ $15 \mathrm{~km}$ đến $50 \mathrm{~km}$, các trung tâm phóng điện có xu thế dịch chuyển dần về phía khu vực Gia Lâm-Hà Nội. Kiểm tra số liệu vệ tinh Himawari, kênh TIR2 và chênh lệch nhiệt độ giữa kênh TIR6 và kênh TIR2 cho thấy: vùng mây có nhiệt độ thấp (nhỏ hơn $230 \mathrm{~K}$, có vùng nhỏ hơn $200 \mathrm{~K}$ ) bao phủ phần lớn khu vực giới hạn $50 \mathrm{~km}$, chênh lệch nhiệt độ giữa hai kênh ở phần lớn khu vực này cũng không lớn (hình 9), ngoại trừ một phần ở phía đông nam trạm. Ảnh radar thời tiết thời điểm 14 giờ, ngày 09/09/2019, trạm Phù Liễn (hình 10) cho thấy có vùng mây ở phía bắc so với trạm Phú Thụy, có độ phản hồi $>35 \mathrm{dBz}$. Do vậy, chúng ta có thể xác định ở khu vực nghiên cứu tồn tại mây đối lưu và qua các bước thời gian, chúng tôi thấy khối mây này đang dịch chuyển dần về phía trạm Phú Thụy. Giá trị điện trường trở nên âm hơn và đạt giá trị vượt ngưỡng (nhỏ hơn $-1 \mathrm{kV} / \mathrm{m}$ ) ở thời điểm 14 giờ 3 phút $\left(\mathrm{T}_{\mathrm{LW}}\right)$, đến thời điểm 14 giờ 50 phút $\left(\mathrm{T}_{\mathrm{LAOC}}\right)$ tại khu vực Gia Lâm-Hà Nội (vùng $\mathrm{AOC}$ ) đã xuất hiện cú sét đầu tiên, xác định được thời gian cảnh báo trước $\mathrm{LT}=47$ phút. Sau thời điểm đó, hoạt động sét càng tiến gần về phía trạm Phú Thụy hơn, gần nhất khoảng 15 giờ 50 phút, thời điểm đó ảnh mây vệ tinh cho thấy khối mây có nhiệt độ thấp nhất, dịch chuyển gần đến trạm. Sau đó, 
hoạt động sét có xu hướng đi ra xa khu vực cảnh báo và quay trở lại khu vực cần cảnh báo vào thời điểm gần 18 giờ và sau thời điểm 20 giờ, cường độ điện trường trở lại trạng thái bình thường.

Hình 12 mô tả biến đổi cường độ điện trường và hoạt động sét trong giới hạn $50 \mathrm{~km}$ xung quanh trạm Phú Thụy, trong khoảng thời gian từ 6 giờ 30 phút đến 17 giờ 30 phút, ngày 16/09/2017. Trong khoảng thời gian từ 7 giờ đến 7 giờ 30 phút, hoạt động sét xẩy ra trong khoảng từ $35 \mathrm{~km}$ đến $50 \mathrm{~km}$, điện trường đo tại trạm Phú Thụy không thay đổi nhiều (nhỏ hơn $500 \mathrm{~V} / \mathrm{m}$ ), do vậy hoạt động dông sét chưa ảnh hưởng đển khu vực Gia Lâm-Hà Nội. Bắt đầu từ gần 9 giờ đến khoảng 11 giờ, hoạt động sét dịch chuyển về phía khu vực Gia LâmHà Nội. Sau khoảng thời gian này, cường độ điện trường đo tại trạm Phú Thụy dần đổi dấu sang giá trị âm. Đạt giá trị vượt ngưỡng (nhỏ hơn $-1 \mathrm{kV} / \mathrm{m}$ ), tại thời điểm 11 giờ 21 phút $\left(\mathrm{T}_{\mathrm{LW}}\right)$. Để xác định vùng mây đối lưu trong khu vực giới hạn $50 \mathrm{~km}$, trong trường hợp này chúng tôi cũng sử dụng số liệu vệ tinh Himawari kênh TIR2 và chênh lệch nhiệt độ giữa kênh TIR6 và kênh TIR2 (hình 11). Ở thời điểm cường độ điện trường vượt ngưỡng, vùng có chênh lệch nhiệt độ giữa hai kênh nhỏ, chỉ chiếm phần nhỏ ở khu vực phía tây trong vùng giới hạn, số liệu ảnh mây ở các bước thời gian trước cho thấy khối mây có xu thế dịch chuyển về phía trạm. Ẩnh radar thời tiết Phù Liễn (hình 13) thời điểm 11 giờ 20 phút cho thấy có mây đối lưu ở vùng giới hạn nghiên cứu. Thông tin cảnh báo sét được xác định cho khu vực Gia Lâm-Hà Nội (tương ứng với vùng $\mathrm{AOC}$ ) được xác định, tiếp sau đó hoạt động sét tiếp tục dịch chuyển dần về vùng $\mathrm{AOC}$ (bán kính $10 \mathrm{~km}$ xung quanh trạm Phú Thụy) đến thời điểm 11 giờ 49 phút, xác định được cú sét đầu tiên trong vùng cần cảnh báo và thời gian cảnh báo trước $\mathrm{LT}=28$ phút $\left(\mathrm{T}_{\mathrm{LAOC}}\right)$. Các thời điểm sau đó, hoạt động sét tiến gần về phía trạm Phú Thụy, gần nhất khoảng gần 13 giờ và kéo dài đến khoảng 14 giờ. Sau thời điểm 14 giờ, hoạt động sét bắt đầu dịch chuyển ra xa khỏi khu vực Gia Lâm-Hà Nội, sau khoảng 17 giờ 30 phút cường độ điện trường trở lại trạng thái bình thường.

Bảng 1. Tổng số ngày có điện trường vượt ngưỡng cảnh báo trên số ngày có số liệu của từng tháng.

\begin{tabular}{ccccccccccccc}
\hline & I & II & III & IV & V & VI & VII & VIII & IX & X & XI & XII \\
\hline 2017 & $\mathrm{NaN}$ & $\mathrm{NaN}$ & $\mathrm{NaN}$ & $3 / 10$ & $5 / 13$ & $\mathrm{NaN}$ & $\mathrm{NaN}$ & $9 / 15$ & $13 / 29$ & $8 / 31$ & $0 / 30$ & $0 / 19$ \\
2018 & $0 / 30$ & $0 / 28$ & $2 / 31$ & $7 / 28$ & $12 / 31$ & $2 / 3$ & $\mathrm{NaN}$ & $\mathrm{NaN}$ & $\mathrm{NaN}$ & $\mathrm{NaN}$ & $\mathrm{NaN}$ & $\mathrm{NaN}$ \\
2019 & $\mathrm{NaN}$ & $\mathrm{NaN}$ & $\mathrm{NaN}$ & $\mathrm{NaN}$ & $8 / 18$ & $13 / 30$ & $15 / 31$ & $20 / 31$ & $11 / 27$ & $9 / 31$ & $2 / 30$ & $0 / 25$ \\
\hline
\end{tabular}

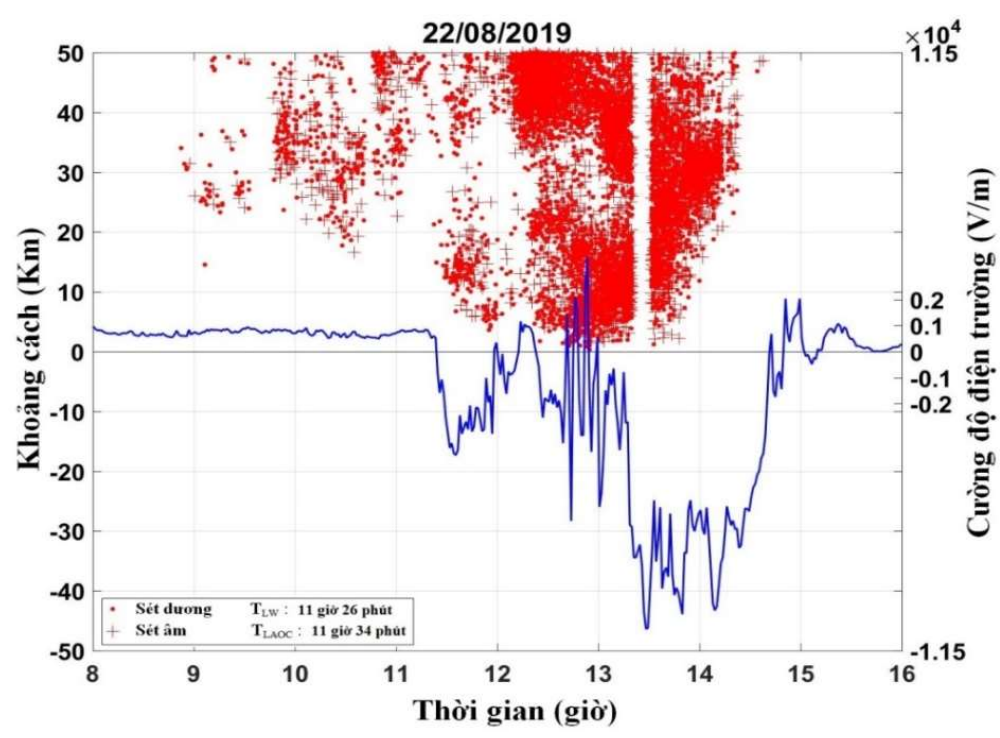


Hình 6. Biến đổi cường độ điện trường trong điều kiện thời tiết xảy ra hoạt động sét ở gần trạm Phú Thụy, trong ngày 22/08/2019.

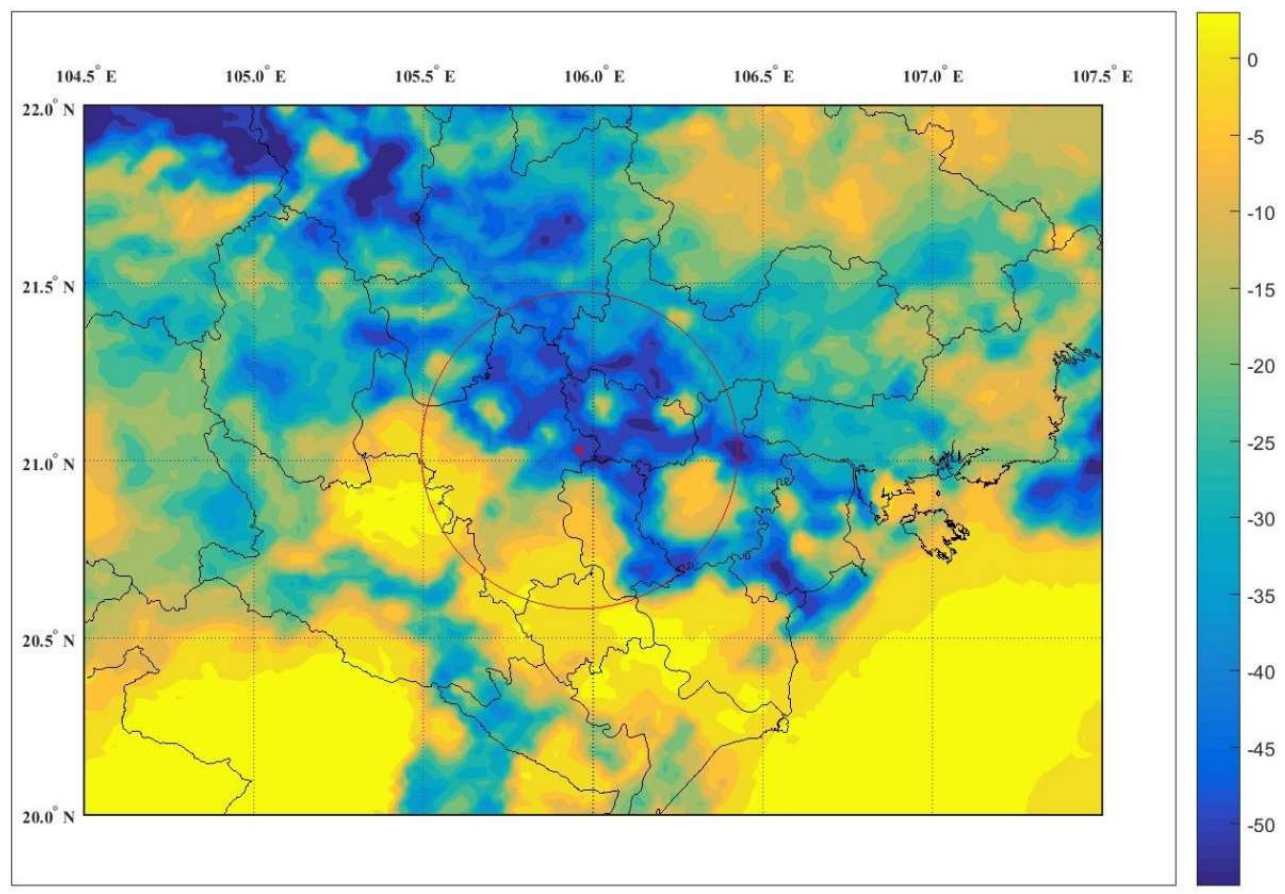

Hình 7. Chênh lệch nhiệt độ kênh hồng ngoại TIR6 $(6.2 \mu \mathrm{m})$ và TIR2 $(11.2 \mu \mathrm{m})$, nhiệt độ $\mathrm{K}$, tại thời điểm 11 giờ 20 phút, ngày 22/08/2019.

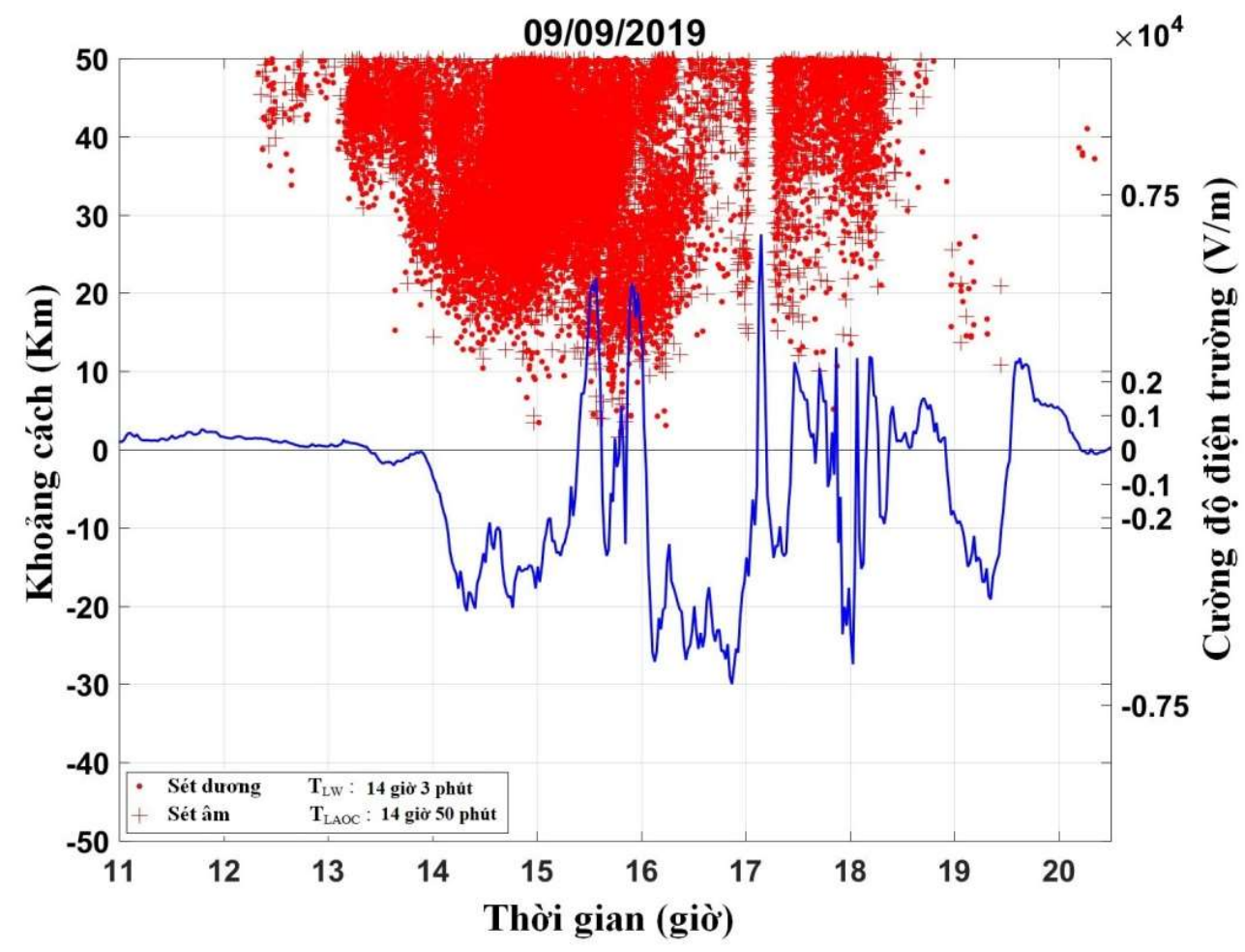


Hình 8. Biến đổi cường độ điện trường trong điều kiện thời tiết xẩy ra hoạt động sét ở gần trạm Phú Thụy, trong ngày 09/09/2019.

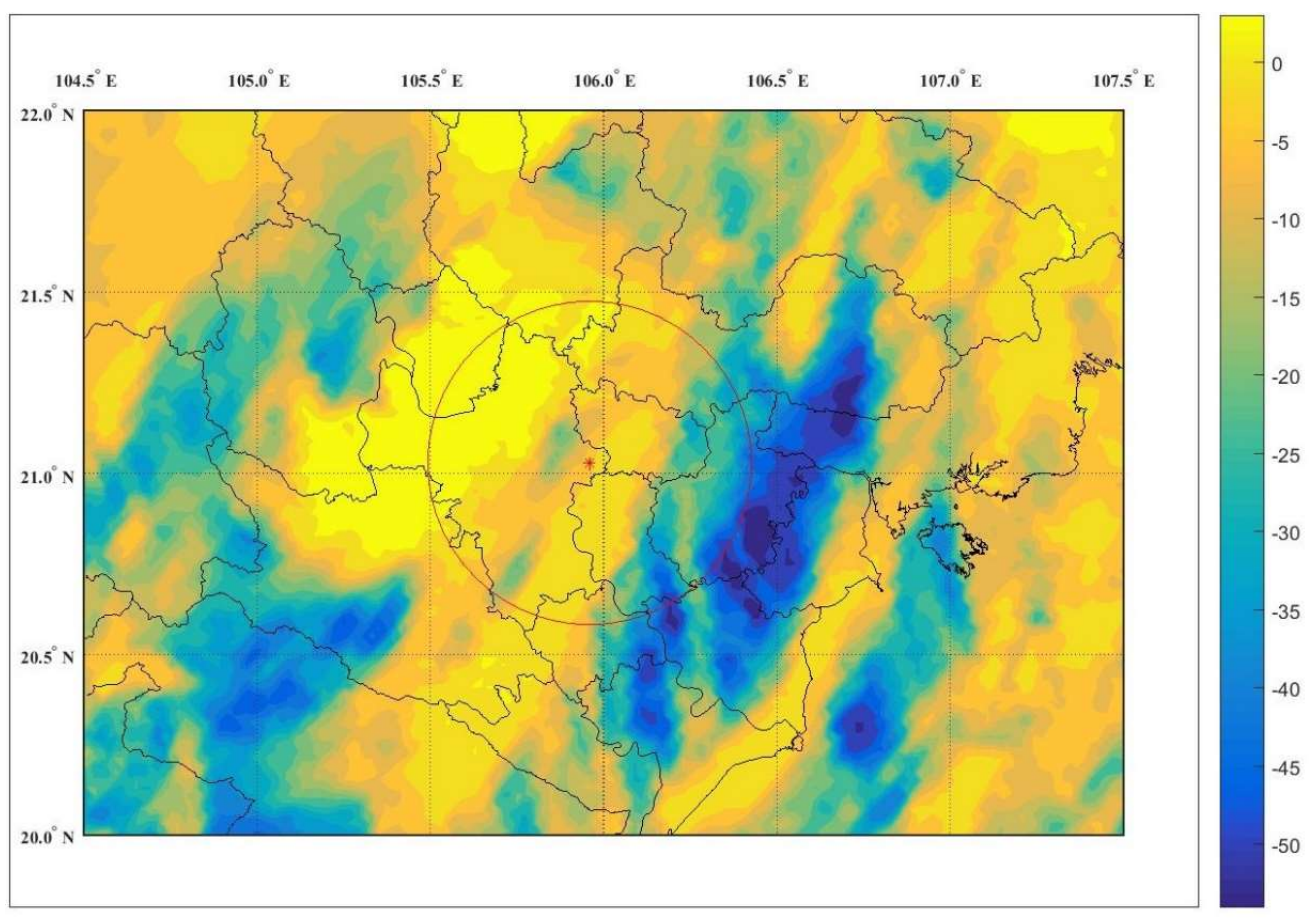

Hình 9. Chênh lệch nhiệt độ kênh hồng ngoại TIR6 $(6.2 \mu \mathrm{m})$ và TIR2 $(11.2 \mu \mathrm{m})$, nhiệt độ $\mathrm{K}$, tại thời điểm 14 giờ, ngày 09/09/2019. 


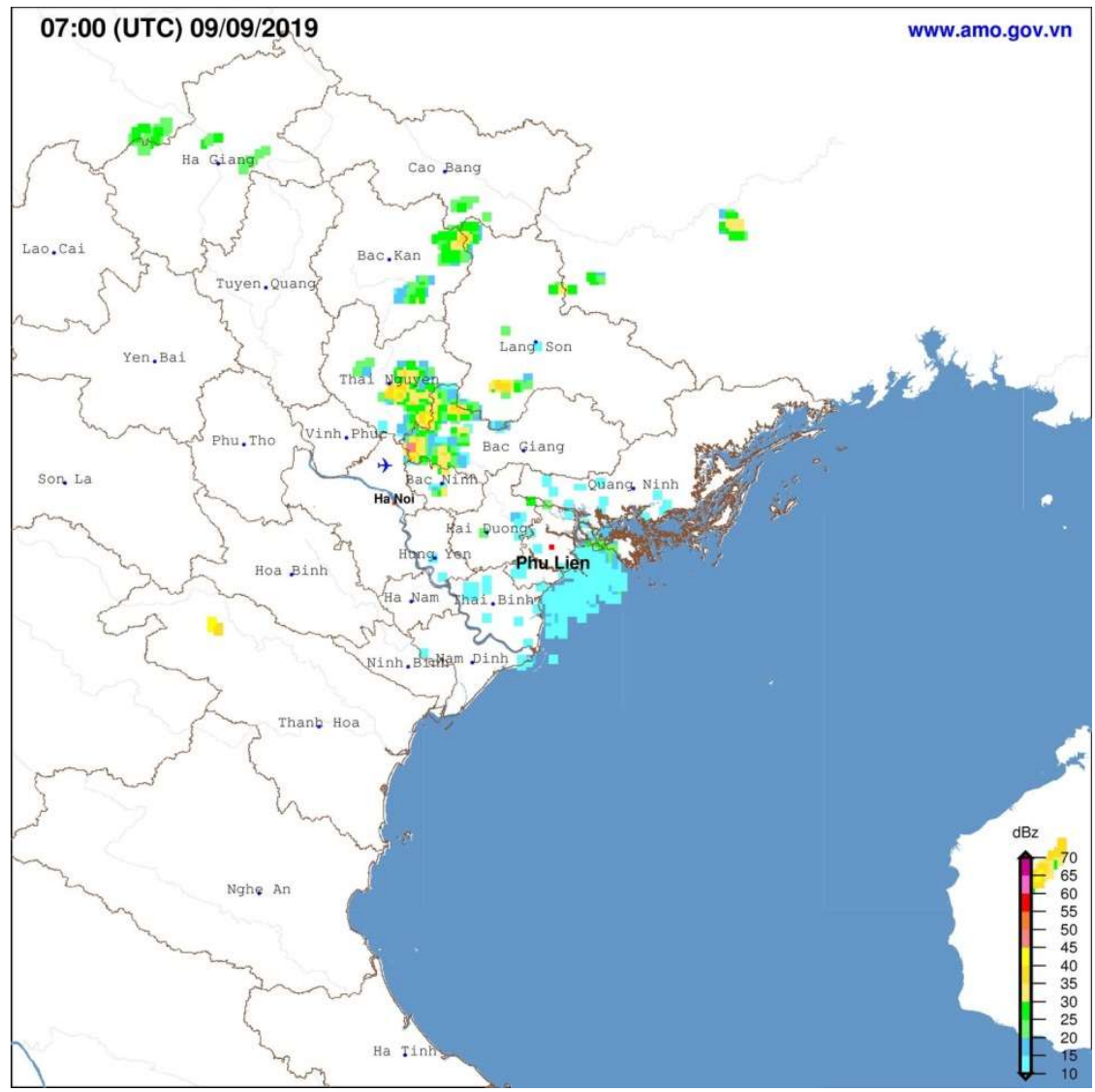

Hình 10. Ảnh radar thời tiết Phù Liễn thời điểm 14 giờ ngày 09/09/2019 (nguồn www.amo.gov.vn).

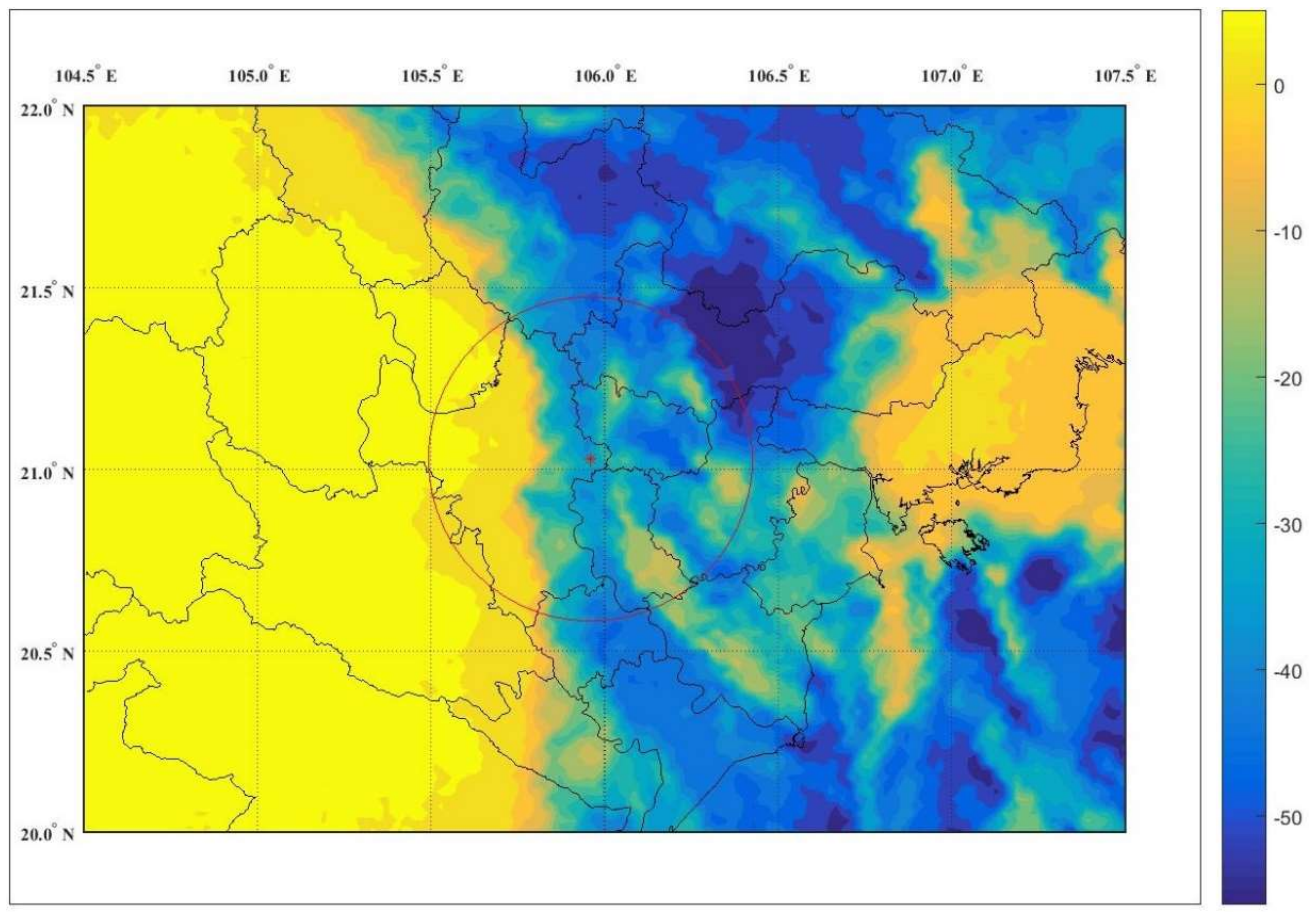

Hình 11. Chênh lệch nhiệt độ kênh hồng ngoại TIR6 $(6.2 \mu \mathrm{m})$ và TIR2 $(11.2 \mu \mathrm{m})$, nhiệt độ $\mathrm{K}$, tại thời điểm 11 giờ 20 phút, ngày 16/09/2017. 


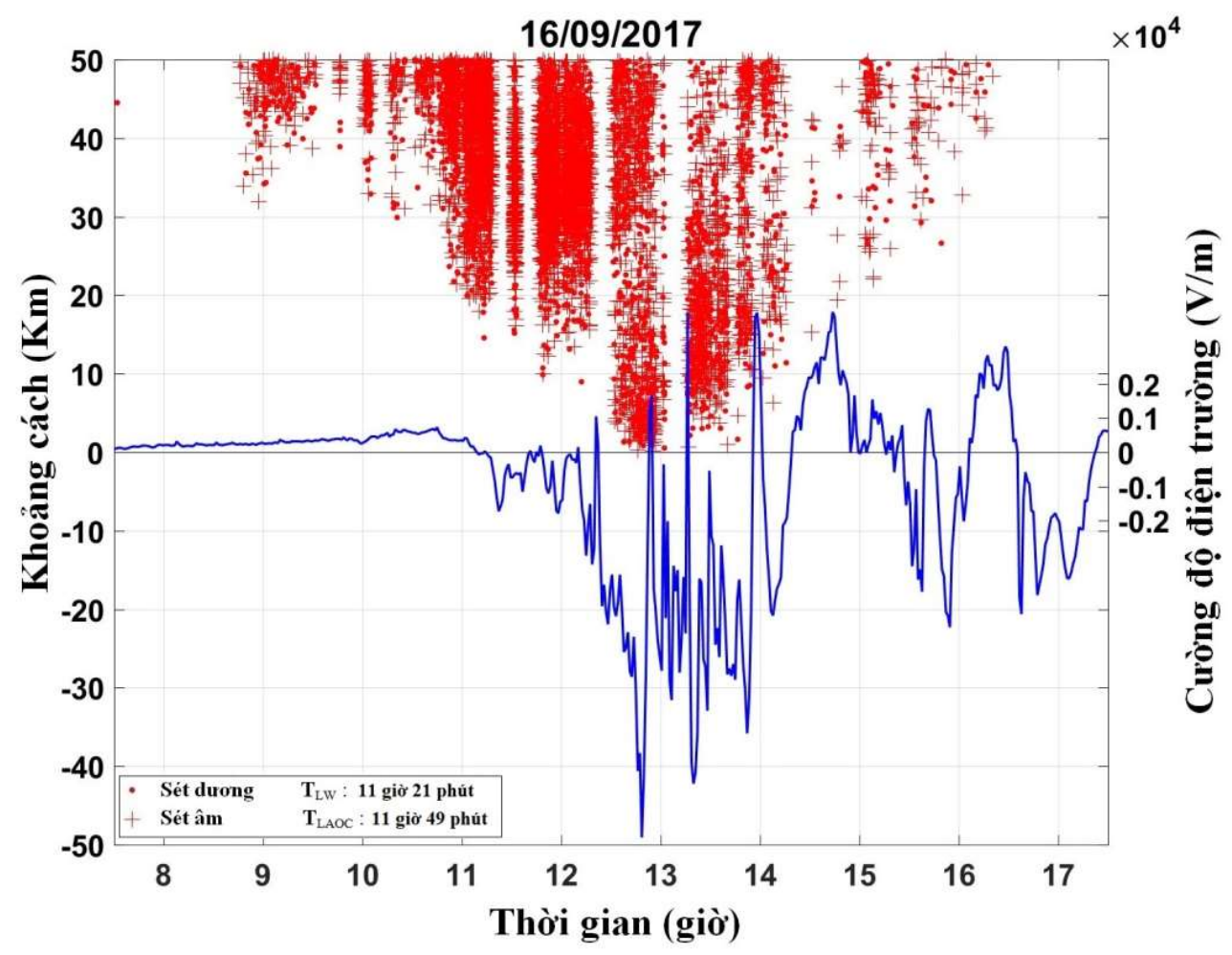

Hình 12. Biến đổi cường độ điện trường trong điều kiện thời tiết xẩy ra hoạt động sét ở gần trạm Phú Thụy, trong ngày 16/09/2017.

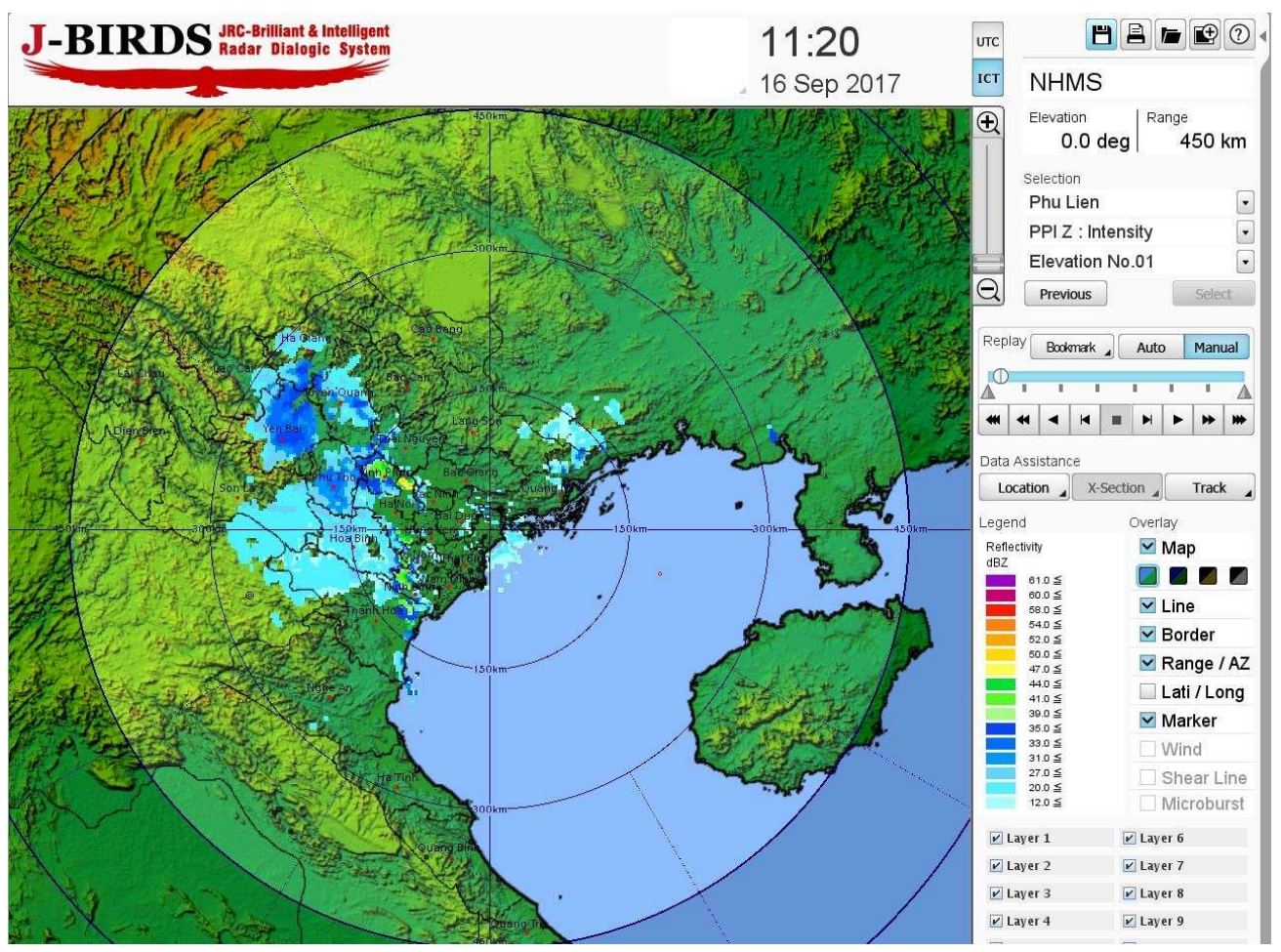

Hình 13. Ảnh radar thời tiết Phù Liễn thời điểm 11 giờ 20 phút ngày 16/09/2017 (nguồn NHMS). 
Bằng cách làm tương tự, chúng tôi tiến hành nghiên cứu cảnh báo sét cho khu vực Gia Lâm-Hà Nội trên toàn bộ số liệu đo, như đã nêu ra ở phần trên, bộ số liệu bao gồm: 97 ngày đo cường độ điện trường, số liệu định vị sét và số liệu vệ tinh Himawari hoặc số liệu radar thời tiết. Ngoài ra chúng tôi cũng phân chia số liệu đo đạc thành hai trường hợp, trường hợp cho cả ngày và trường hợp sau buổi trưa. Kết quả tính toán, đánh giá kết quả cảnh báo được trình bày trong hình 14 và hình 15 . Hình 14 , biểu diễn kết quả xác định các chỉ số $\mathrm{POD}, \mathrm{FTW}$ và $\mathrm{FAR}$. Tỷ lệ cảnh báo đúng (xác xuất phát hiện) $\mathrm{POD}$, liên quan đến số lấn cảnh báo thành công, số lần cảnh báo đúng xầy ra phóng điện trong vùng $\mathrm{AOC}$ và số lần không đưa ra thông tin cảnh báo nhưng sét vẫn xẩy ra ở trong vùng $\mathrm{AOC}$, kết quả cho toàn bộ tập số liệu giá trị $\mathrm{POD}=86,99 \%$ và giới hạn thời gian sau buổi trưa giá trị $\mathrm{POD}=88,0 \%$. Giá trị $\mathrm{POD}$ giới hạn sau trưa cao hơn POD giới hạn theo ngày là do các cơn dông diễn ra sau buổi trưa thường xẩy ra mạnh hơn thời gian buổi sáng [2], do vậy khả năng phát hiện dông sét của các thiết bị nghiên cứu dông sét vào thời gian sau trưa sẽ lớn hơn. Từ biểu đồ cũng như tỷ lệ cảnh báo đúng chúng tôi cũng xác định được tỷ lệ cảnh báo không thành công FTW, cho trường hợp theo ngày $\mathrm{FTW}=13,1 \%$ và trường hợp sau trưa $\mathrm{FTW}=12,0 \%$. Tỷ lệ cho biết tại khu vực Gia Lâm-Hà Nội với thiết bị hiện có, cứ 100 trường hợp cảnh báo sét thì có khoảng 87 trường hợp đúng và khoảng 13 trường hợp sai. Tỷ lệ cảnh báo khống FAR, liên quan thông tin cảnh báo được đưa ra nhưng sét lại không xẩy ra ở vùng cần cảnh báo (AOC). Những nguyên nhân dần đến những trường hợp cảnh báo khống bao gồm: có trường hợp mây dông chỉ di chuyển đến vùng WA hoặc phát triển trong vùng này, nhưng không di chuyển vào vùng cần cảnh báo $(\mathrm{AOC})$; thiết bị định vị sét có sai số đưa đến vị trí định vị nhầm vào vùng WA làm cảnh báo được kích hoạt; những biến đổi bất thường về môi trường khí quyển như sự gia tăng hạt nhân ngưng kết làm cường độ điện trường vượt ngưỡng cũng là nguyên nhân làm tăng cảnh báo khống. FAR theo toàn bộ thời gian trong ngày đạt $24,14 \%$ và theo thời gian sau trưa $18,52 \%$. Giá trị FAR của thời gian sau trưa nhỏ hơn giá trị $\mathrm{FAR}$ cả ngày là do tỷ lệ cảnh báo sai của cả ngày lớn hơn thời gian sau trưa, do dông sét sau trưa thường mạnh hơn nên khả năng phát hiện của thiết bị để cảnh báo dông sét cũng sẽ lớn hơn, tương tự giá trị POD.

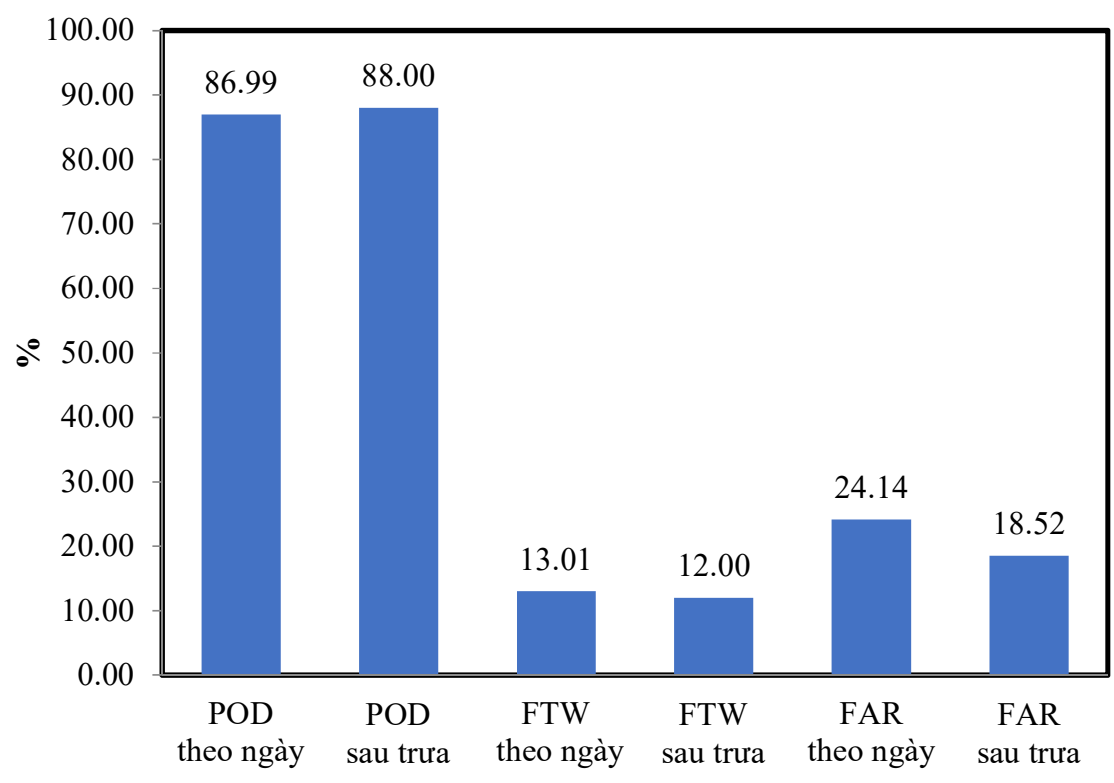

Hình 14. Biểu đồ so sánh các tham số đánh giá kết quả cảnh báo sét tại khu vực Gia Lâm-Hà Nội. 


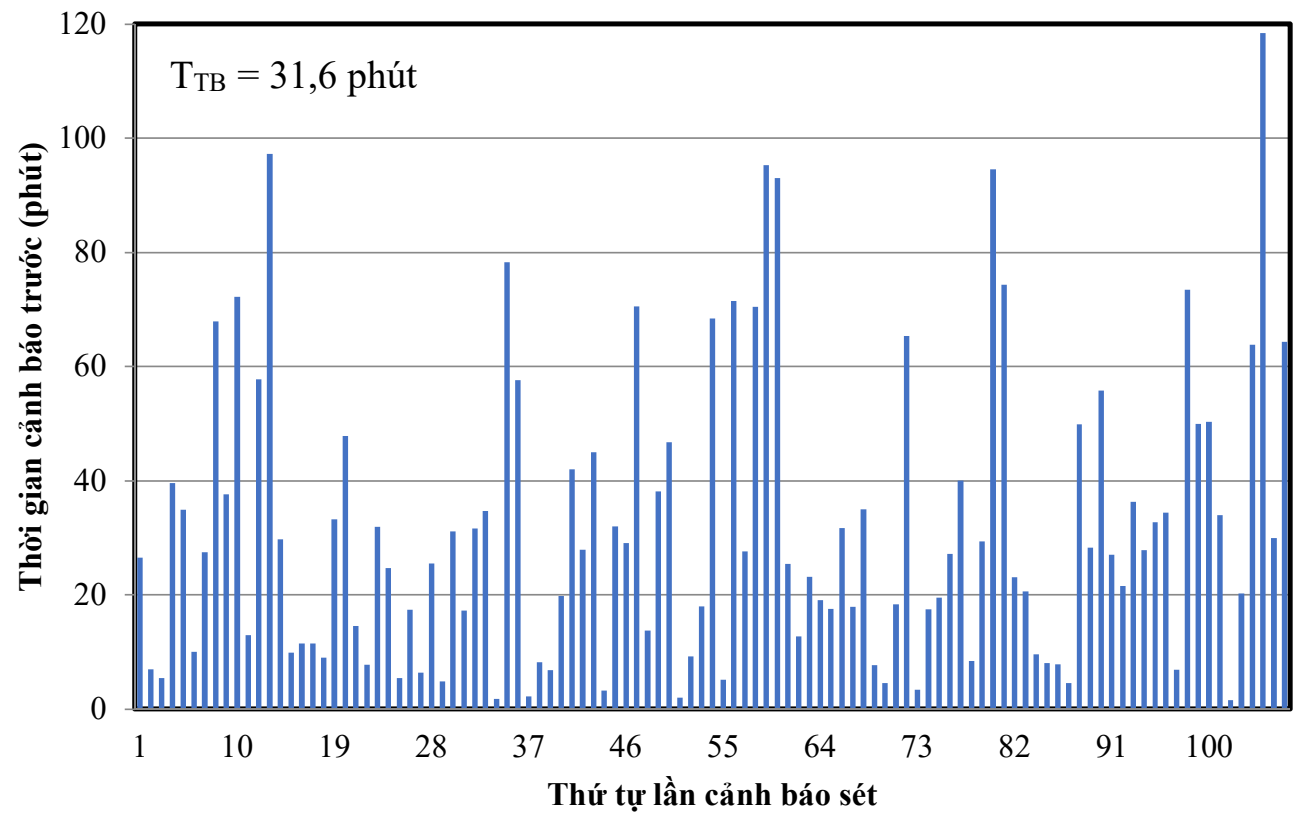

Hình 15. Biến đổi thời gian cảnh báo sét trước (LT: Lead Time), theo thứ tự lần cảnh báo sét cho khu vực Gia Lâm-Hà Nội.

Hình 15, mô tả biến đổi thời gian cảnh báo sét trước (LT), theo thứ tự các lần cảnh báo sét của 107 lần trong 97 ngày (từ 2017 đến 2019). Việc cảnh báo sét sớm hay trễ hơn đều có ý nghĩa, phụ thuộc vào từng bài toán cụ thể, biến đổi giá trị này thay đổi từ một vài phút đến dưới 120 phút (hình 15), giá trị trung bình đạt 31,6 phút, giá trị này phù hợp với nhiều nghiên cứu trước đây của rất nhiều tác giả trên thế giới như trong $[7,8,13,19]$. Thời gian cảnh báo sét trước trung bình được nhóm tác giả trong công trình [8], xác định LT $=20,0$ phút, POD $=80,0 \%$. Tuy nhiên, trong nghiên cứu này nhóm tác giả chỉ sử dụng số liệu cường độ điện trường và số liệu định vị sét. Trong khi đó, trong nghiên cứu của chúng tôi đã sử dụng tổng hợp các nguồn số liệu (điện trường, định vị sét, số liệu radar thời tiết, số liệu vệ tỉnh), làm tăng mức độ chính xác cảnh báo sét $(\mathrm{POD}=86,99 \%)$ và thời gian trung bình cảnh báo sét trước cũng lớn hơn, cho khu vực Gia Lâm-Hà Nội.

\section{Kết luận}

Trên cơ sở bộ số liệu tổng hợp gồm: số liệu cường độ điện trường, số liệu định vị sét, số liệu radar thời tiết và số liệu vệ tinh trong khoảng thời gian từ 2017 đến 2019 , chúng tôi tiến hành nghiên cứu thử nghiệm cảnh báo sét và đánh giá kết quả cho khu vực Gia Lâm-Hà Nội, từ các kết quả trình bày ở trên có thể rút ra một số kết luận sau:

Trên toàn bộ tập số liệu thu thập và đánh giá cho hai trường hợp thời gian cả ngày và thời gian buổi chiều, tỷ lệ cảnh báo đúng (POD) tương ứng là $86,99 \%$ và $88,00 \%$, tỷ lệ cảnh báo không thành công (FTW) tương ứng là $13,01 \%$ và $12,0 \%$ và tỷ lệ cảnh báo khống (FAR) tương ứng là $24,14 \%$ và $18,52 \%$. Tỷ lệ cảnh báo sét đúng tại khu vực Gia Lâm-Hà Nội vào thời gian sau buổi trưa lớn hơn cả ngày là do tại khu vực này hoạt động dông sét vào thời điểm sau buổi trưa thường xẩy ra nhiều và mạnh. Thời gian cảnh báo sét trước trung bình cho khu vực Gia Lâm-Hà Nội bằng 31,6 phút, giá trị này phù hợp và lớn hơn (tốt hơn) một số giá trị được xác định trong một số nghiên cứu trên thế giới.

Nghiên cứu này cho thấy khả năng cảnh báo sét thành công cho khu vực Gia Lâm-Hà Nội với tỷ lệ cảnh báo đúng lớn (gần 90\%), thời gian cảnh báo sét trước trung bình phù hợp 
các nghiên cứu khác trên thế giới. Trong thời gian kế tiếp, chúng tôi sẽ nghiên cứu trên các vùng rộng hơn như toàn bộ khu vực Hà Nội, Quảng Nam, Vũng Tàu hay Quảng Ninh, đây là các khu vực thường xuyên chịu ảnh hưởng của sét, bên cạnh đó những nơi này cũng đã được hoặc mới lắp đặt mạng lưới trạm đo điện trường.

Đóng góp của tác giả: Xây dựng ý tưởng nghiên cứu: H.H.S., N.X.A, P.X.T, N.V.H; Lựa chọn phương pháp nghiên cứu: N.X.A, P.X.T, N.V.H; Xử lý số liệu: H.H.S.; Viết bản thảo bài báo: H.H.S., N.X.A, P.X.T, N.V.H; Chỉnh sửa bài báo: H.H.S., N.X.A, P.X.T, N.V.H.

Lò̀i cảm ơn: Nhóm tác giả chân thành cảm ơn sự hỗ trợ cho nghiên cứu này từ Dự án "Ứng dụng công nghệ tự động hóa trong quá trình sản xuất nguyên liệu và quá trình sản xuất, chế biến chè xanh sao lăn chất lượng cao tại công ty cổ phần trà Than Uyên”, mã số: CNC 003/19. Nhóm tác giả cũng xin cảm ơn tiểu Dự án FIRST-IGP: "Thiết lập hệ thống quan trắc tăng cường và hệ thống dự báo, cảnh báo độ phân giải cao hạn ngắn, cực ngắn dông, mưa lớn và ngập lụt đô thị cho thành phố Hà Nội phục vụ phát triển kinh tế, đảm bảo an sinh xã hội" thuộc dự án FIRST: "Đẩy mạnh đổi mới sáng tạo thông qua nghiên cứu, khoa học và công nghệ" do Ngân hàng Thế giới tài trợ đã cho sử dụng tài nguyên tính toán từ hệ thống máy tính hiệu năng cao phục vụ tính toán, thu thập, xử lý số liệu trong quá trình thực hiện nghiên cứu này; cảm ơn Đài Khí tượng Cao không, Tổng cục Khí tượng Thủy văn đã chia sẻ dữ liệu radar Phù Liễn (Hình 10 và Hình 13), cảm ơn Cơ quan Khí tượng Nhật Bản (Japan Meteorological Agency) đã cung cấp số liệu vệ tinh Himawari cho nghiên cứu.

Lời cam đoan: Tập thể tác giả cam đoan bài báo này là công trình nghiên cứu của tập thể tác giả, chưa được công bố ở đâu, không được sao chép từ những nghiên cứu trước đây; không có sự tranh chấp lợi ích trong nhóm tác giả.

\section{Tài liệu tham khảo}

1. Anh, N.X. và cs. Nghiên cứu hoạt động dông sét và đề xuất các giải pháp phòng chống ở Việt Nam. Báo cáo tổng kết Đề tài cấp Nhà nước, 2005, tr. 252.

2. Anh, N.X.; Huy, L.V.; Sơn, H.H. Một số kết quả nghiên cứu hoạt động dông sét qua mạng trạm định vị sét ở Việt Nam. Tuyển tập báo cáo Hội nghị Khoa học kỹ thuật Địa Vật lý lần thứ 5. Nhà xuất bản khoa học kỹ thuật, 2007, 11-20.

3. Anh, N.X.; Huy, L.V.; Sơn, H.H. Nghiên cứu hoạt động dông sét và giải pháp phòng chống ở Việt Nam: Một số kết quả và phương hướng nghiên cứu. Tuyển tập các công trình nghiên cứu Vật lý Địa cầu 2008. Viện Khoa học và Công nghệ Việt Nam, 2008, 289-306.

4. Anh, N.X. và cs. Nghiên cứu và đề xuất các giải pháp phòng chống sét trên địa bàn tỉnh Quảng Nam. Báo cáo tổng kết Đề tài cấp Bộ, 2013, tr. 188.

5. Sơn, H.H.; Anh, N.X.; Huy, L.V.; Thành P.X. Xác định một số tham số hoạt động dông sét từ chuỗi số liệu mô phỏng. Tap chí Các khoa học về Trái đất 2011, 2, 134-141.

6. Sơn, H.H.; Anh, N.X. Xác định khu vực hoạt động của mây dông theo số liệu cường độ điện trường tại Quảng Nam.Tuyển tập báo cáo Hội nghị khoa học quốc tế: Vật lý Địa cầu-Hợp tác và phát triển bền vững, 2012, 23-30.

7. Murphy, M.J.; Holle, R.L. Warnings of cloud-to-ground lightning hazard based on combinations of lightning detection and radar information. $24^{\text {th }}$ International Lightning Detection Conference $\& 6^{\text {th }}$ International Lightning Meteorology, 2006.

8. Murphy, M.J.; Said, R.K. Preliminary Analysis of Lightning Warnings in and near the Rocky Mountains using U.S. National Lightning Detection Network and Electric Field Mill Data. 24th International Lightning Detection Conference \& 6th International Lightning Meteorology Conference, 2016.

9. Montanya, J.; Bergas, J.; Hermoso, B. Electric field measurements at ground level as a basis for lightning hazard warning. J. Electrostat. 2004, 60, 241-246. https://doi.org/10.1016/j.elstat.2004.01.009 
10. Montanya, J.; Rodri'guez, P.; Bergas, J., Illa, A.; Hermoso, B.; Candela, I. A new electrostatic field measurement method: the Coherent-Notch Field Mill. J. Electrostat. 2007, 6, 431-437. https://doi.org/10.1016/j.elstat.2006.10.005

11. Montanya, J.; Aranguren, D.; Pineda, N.; Sola, G. Total lightning, electrostatic meteorological radar applied to lightning hazard warning. $20^{\text {th }}$ International Lightning Detection Conference, Tucson, AZ, 2008.

12. Beasley, W.H.; Williams, D.E.; Hyland, P.T. Analysis of surface electric-field contours in relation to cloud-to-ground lightning flashes in air-mass thunderstorms at the Kennedy Space Center. Procceding of $20^{\text {th }}$ International Lightning Detection Conference, 2008.

13. Aranguren, D.; Montanya, J.; Solá, G.; March, V.; Romero, D.; Torres, H. On the lightning hazard warning using electrostatic field: Analysis of summer thunderstorms in Spain. $J$. Electrostat. 2009, 67, 507-512. https://doi.org/10.1016/j.elstat.2009.01.023

14. Ferro, M.A.D.S.; Yamasaki, J.; Pimentel, D.R.D.M.; Naccarato, K.P.; Saba, M.M.F. Lightning risk warnings based on atmospheric electric field measurements in Brazil. $J$. Aerosp.Technol. Manag. 2011, 3, 301-310. https://doi.org/10.5028/jatm.2011.03032511

15. Kohn, M.; Galanti, E.; Price, C.; Lagouvardos, K.; Kotroni, V. Nowcasting thunderstorms in the Mediterranean region using lightning data. Atmos. Res. 2011, 100, 489-502. https://doi.org/10.1016/j.atmosres.2010.08.010

16. Mosier, R.M.; Schumacher, C.; Orville, R.E.; Carey, L.D. Radar Nowcasting of Cloud-toGround Lightning over Houston, Texas. Weather and Forecasting 2011, 26, 199-212. https://doi.org/10.1175/2010WAF2222431.1

17. López, J.; Pérez, E.; Herrera, J.; Aranguren, D.; Porras, L. Thunderstorm warning alarms methodology using electric field mills and lightning location networks in mountainous regions. International Conference on Lightning Protection, 2012. https://doi.org/10.1109/ICLP. 2012.6344397

18. Seroka, G.N.; Orville, R.E.; Courtney, S. Radar Nowcasting of Total Lightning over the Kennedy Space Center. Weather Forecasting 2012, 27, 189-204. https://doi.org/10.1175/WAF-D-11-00035.1

19. Zeng, Q.; Wang, Z.; Guo, F.; Feng, M.; Zhou, S.; Wang, H.; Xu, D. The application of lightning forecasting based on surface electrostatic field observations and radar data. $J$. Electrostat. 2013, 71, 6-13. https://doi.org/10.1016/j.elstat.2012.10.007

20. Srivastava, A.; Mishra, M.; Kumar, M. Lightning alarm system using stochastic modelling. Nat Hazards. 2015, 75, 1-11. DOI 10.1007/s11069-014-1247-8

21. Junchi, Z.; Qingfeng, Z.; Shah, A.B.; Xue, J.; Ye, Z. A Lightning Warning Algorithm Using a EFMs Network and LPS. Pakistan J. Meteorol. 2015, 12, 49-55.

22. Karagiannidis, A.; Lagouvardos, K.; Kotroni, V. The use of lightning data and Meteosat infrared imagery for the nowcasting of lightning activity. Atmos. Res. 2016, 168, 57-69. https://doi.org/10.1016/j.atmosres.2015.08.011

23. Tao, H.; Gu, S.; Wang, H.; Feng, W.; Guo, J.; Wang, Y.; Zhang, L. Method of lightning warning based on atmospheric electric field and lightning location data. $201633^{\text {rd }}$ International Conference on Lightning Protection (ICLP), 2016. https://doi.org/10.1109/iclp.2016.7791394

24. Holle, R.L.; Nicholas; Demetriades, W.S.; Nag A. Objective Airport Warnings over Small Areas Using NLDN Cloud and Cloud-to-Ground Lightning Data. Weather Forecasting 2016, 31, 1061-1069. https://doi.org/10.1175/WAF-D-15-0165.1

25. Trung L.B.; Toán H.M.; Phong N.B. Nghiên cứu sử dụng số liệu định vị sét kết hợp với ảnh radar để cảnh báo đợt mưa lớn từ 01-06/8/2017 trên khu vực Tây Bắc. Tạp chí Khí tượng Thủy văn 2018, 685, 48-54.

26. https://www.boltek.com/EFM-100C_Manual_121415.pdf

27. Lee, S.; Han, H.; Im, J.; Jang, E.; Lee, M.I. Detection of deterministic and probabilistic convection initiation using Himawari-8 Advanced Himawari Imager data. Atmos. Meas. Tech. 2017, 10, 1859-1874. https://doi.org/10.5194/amt-10-1859-2017

28. Thư, N.V. Nghiên cứu phương pháp phân loại mây từ thông tin vệ tinh địa tĩnh MTSAT. Tạp chí Khi tương Thủy văn 2017, 675, 27-34. 


\title{
A research on lightning warning by integated data: a case study for Gialam area, Hanoi city
}

\author{
Hoang Hai Son ${ }^{1,2 *}$, Nguyen Xuan Anh ${ }^{1,2}$, Pham Xuan Thanh ${ }^{1,2}$, Nguyen Van Hiep ${ }^{1,3}$ \\ 1 Institute of Geophysics, hhson@igp-vast.vn; anhnx@igp-vast.vn; pxthanh@igp-vast.vn \\ 2 Graduate University of Science and Technology, hhson@igp-vast.vn; anhnx@igp-vast. \\ vn; pxthanh@igp-vast.vn \\ 3 Northern Delta Regional Hydro-Meteorological Center, hiepwork@gmail.com
}

\begin{abstract}
This paper evaluates and develops a lightning warning procedure for GialamHanoi area. Data used include as follows: 139 days of disturbance of electric intensity from a total of 521 days of observation from the EFM-100 device located at Phuthuy Station in Gialam-Hanoi during the period from 2017 to 2019; the lightning position data; weather radar data; and Himawari satellite data. The "two-zone" warning method was applied in which the AOC alarm zone has a radius of $10 \mathrm{~km}$ from the site of the electric field station and the WA warning zone has a radius of $30 \mathrm{~km}$ from the station. The statistical indicators were used to evaluate warning quality for whole-day case and afternoon-only case. The results showed that the correct warning rate (POD) for the AOC region were $86.99 \%$ and $88.0 \%$ for whole-day and afternoon cases, respectively. The failure to warn (FTW) for the AOC regions are $13.01 \%$ and $12 \%$ for the two cases, respectively. The false alarm rates (FAR) are $24.14 \%$ and $18.52 \%$, respectively. Average lightning warning time is 31.6 minutes in advance. Warning period of 30 minutes in advance are quite useful time to lightning prevention and preparation for many areas in socially economic society.
\end{abstract}

Keywords: Atmospheric electric field; Lightning detection; Weather radar; Satellite cloud image. 